\title{
TITLE:
}

\section{Horizontal profile of a moving red line cusp aurora}

$\operatorname{AUTHOR}(\mathrm{S}):$

Taguchi, S.; Chiba, Y.; Hosokawa, K.; Ogawa, Y.

CITATION:

Taguchi, S. ...[et al]. Horizontal profile of a moving red line cusp aurora. Journal of Geophysical Research: Space Physics 2017, 122(3): 3509-3525

ISSUE DATE:

2017-03

URL:

http://hdl.handle.net/2433/228286

\section{RIGHT:}

(C)2017. American Geophysical Union.; The full-text file will be made open to the public on 18 October 2017 in accordance with publisher's 'Terms and Conditions for Self-Archiving'. 


\section{Journal of Geophysical Research: Space Physics}

\author{
RESEARCH ARTICLE \\ 10.1002/2016JA023115 \\ Key Points: \\ - A semiquantitative model explains the \\ intensity variation of a moving red line \\ cusp aurora \\ - A moving red line cusp aurora does \\ not have electron precipitation in its \\ rear half \\ - The velocity of the electron \\ precipitation region is important for \\ determining how the red line aurora \\ extends horizontally
}

Supporting Information:

- Supporting Information S1

- Animation S1

Correspondence to:

S. Taguchi,

taguchi@kugi.kyoto-u.ac.jp

\section{Citation:}

Taguchi, S., Y. Chiba, K. Hosokawa, and Y. Ogawa (2017), Horizontal profile of a moving red line cusp aurora, J. Geophys. Res. Space Physics, 122, 3509-3525, doi:10.1002/2016JA023115.

Received 26 JUN 2016 Accepted 7 FEB 2017

Accepted article online 13 FEB 2017

Published online 7 MAR 2017

C2017. American Geophysical Union. All Rights Reserved.

\section{Horizontal profile of a moving red line cusp aurora}

\author{
S. Taguchi' ${ }^{1}$, Y. Chiba ${ }^{2}$, K. Hosokawa ${ }^{2,3}$ (D) and Y. Ogawa ${ }^{4,5}$ (D) \\ ${ }^{1}$ Department of Geophysics, Graduate School of Science, Kyoto University, Kyoto, Japan, ${ }^{2}$ Department of Communication \\ Engineering and Informatics, University of Electro-Communications, Tokyo, Japan, ${ }^{3}$ Center for Space Science and Radio \\ Engineering, University of Electro-Communications, Tokyo, Japan, ${ }^{4}$ National Institute of Polar Research, Tokyo, Japan, \\ ${ }^{5}$ Department of Polar Science, SOKENDAI (Graduate University for Advanced Studies), Kanagawa, Japan
}

Abstract Auroral emission at a wavelength of $630.0 \mathrm{~nm}$ (red line) has a long radiative time. In this study, we show how this long radiative time controls the horizontal extent of a moving mesoscale aurora, which is typical of the cusp. Using high time resolution ( 4 s) observations by an all-sky imager at Longyearbyen, Svalbard, and observations by the European Incoherent Scatter Svalbard Radar (ESR), we examined the auroral emission enhancements obtained in the cusp during an interval of southward interplanetary magnetic field on 27 November 2011. Simultaneous observations from the all-sky imager and the ESR clearly show the manner in which auroral emission regions passed through the radar's field of view. When the front edge of the moving auroral structure intersected the radar's field of view, the ESR electron temperature was enhanced. A few minutes later, the ESR electron temperature dropped to the background level, indicating that the mesoscale electron precipitation region shifted away from the radar's field of view. At that time, the auroral emission in the radar's field of view decreased but still had adequate intensities. These results provide evidence demonstrating that moving cusp auroral emission occurs behind the electron precipitation region as well as inside that region. We interpreted this feature semiquantitatively by using the equation of continuity of the density of the excited atomic oxygen. Our model indicates that the maximum intensity in the moving auroral structure occurs at a point along the trailing edge of the electron precipitation region and that the velocity of that region is important for determining how the $630.0 \mathrm{~nm}$ aurora emissions extend horizontally.

\section{Introduction}

A moving mesoscale aurora at a wavelength of $630.0 \mathrm{~nm}$ (red line) is a typical phenomenon in the dayside cusp of the high-latitude ionosphere [e.g., Sandholt et al., 1986, 1990; Lockwood et al., 1989; Fasel, 1995] and is thought to be caused by enhanced fluxes of soft magnetosheath electrons in the moving flux tube driven by intermittent reconnection, i.e., a flux transfer event [Haerendel et al., 1978; Russell and Elphic, 1978]. The latitudinal motion of the moving red line cusp aurora typically has velocities ranging from $0.5 \mathrm{~km} \mathrm{~s}^{-1}$ to $1 \mathrm{~km} \mathrm{~s}^{-1}$ and occasionally up to $1.5 \mathrm{~km} \mathrm{~s}^{-1}$ [e.g., Vorobjev et al., 1975; Sandholt et al., 1990]. This motion can be even faster in the longitudinal direction [e.g., Lockwood et al., 1989; Sandholt et al., 1990; Moen et al., 1995; Suzuki et al., 2008; Taguchi et al., 2009]. The moving red line cusp aurora typically has a latitudinal extent of 100-200 km [e.g., Sandholt et al., 1986, 1990] and sometimes has a shorter extent of $\sim 50 \mathrm{~km}$ [e.g., Sandholt et al., 1990; Oksavik et al., 2004; Taguchi et al., 2012].

Most of the aforementioned studies are based on the results of an all-sky imager, which is a powerful tool for obtaining information on the two-dimensional extent of the moving electron precipitation region. This feature is important for examining the evolution of the reconnected flux tube. The data obtained by a spacecraft at ionospheric heights would simply reflect the spatial structure inside the particle precipitation region without providing any information on its evolution. The extent of the moving red line aurora roughly agrees with the extent of the soft electron precipitation region. To obtain more detailed relationships between these two regions, we need to consider that the red line aurora is not prompt emission.

The red line emission originates from $O\left({ }^{1} D\right)$ atoms. Theoretically, the $O\left({ }^{1} D\right)$ state has a lifetime of $110 \mathrm{~s}$. Moreover, its lifetime is reduced to $30-80 \mathrm{~s}$ at the typical altitude of the aurora, i.e., $250-300 \mathrm{~km}$ [e.g., Sipler and Biondi, 1972], owing to the quenching of $\mathrm{O}\left({ }^{1} D\right)$ by its reactions with $\mathrm{N}_{2}, \mathrm{O}_{2}$, and $\mathrm{O}$. When $1 \mathrm{~km} \mathrm{~s}^{-1}$ is taken as the typical speed of the moving cusp auroral structure, any effect from the relatively long lifetime of 30$80 \mathrm{~s}$ at the typical altitude of the $630.0 \mathrm{~nm}$ aurora might be seen across horizontal distances of $30 \mathrm{~km}$ 
$\left(=1 \mathrm{~km} \mathrm{~s}^{-1} \times 30 \mathrm{~s}\right)-80 \mathrm{~km}\left(=1 \mathrm{~km} \mathrm{~s}^{-1} \times 80 \mathrm{~s}\right)$. These distances are not negligible when the mesoscale structure of the moving cusp aurora is considered.

By examination of a moving cusp aurora structure with a typical horizontal scale of roughly $100 \mathrm{~km} \times 200 \mathrm{~km}$, Taguchi et al. [2015a] indicated that the maximum $630.0 \mathrm{~nm}$ intensity of the auroral structure occurs immediately behind the moving $F$ region-enhanced electron density volume created by precipitating electrons. This indication is based on the delay of the auroral intensity peak of approximately $40 \mathrm{~s}$ from the peak of the electron density [Taguchi et al., 2015a, Figures 8a and 8b]. This delay time is consistent with the lifetime of $O\left({ }^{1} D\right)$, which suggests that the spatial relationship obtained by Taguchi et al. [2015a], such that the maximum $630.0 \mathrm{~nm}$ intensity in the cusp auroral structure is located immediately behind the enhanced electron density volume created by the precipitating electrons, is related to the relatively long lifetime of $O\left({ }^{1} D\right)$. The aurora structure analyzed in Taguchi et al. [2015a], however, was not a completely isolated auroral event as explicitly stated in the paper. The data obtained after time 7, as shown in their Figure 8a, reflect variations associated with a different moving auroral structure that appeared immediately after the auroral structure examined in that paper. More detailed relationships of the $630.0 \mathrm{~nm}$ auroral emission region extension from the electron precipitation region need to be clarified.

In the present paper, we examine multiple events of isolated moving cusp aurora by using aurora image data having higher time resolution than those used in Taguchi et al. [2015a]. Moreover, we investigate plasma data from the European Incoherent Scatter (EISCAT) Svalbard radar (ESR), in which the beam passes through the moving auroral structure. On the basis of the ESR and auroral intensity data, we show the larger horizontal extension of the moving cusp aurora compared with the electron precipitation region, and we interpret the characteristics of its horizontal extension in terms of the equation of continuity of the density of the excited atomic oxygen.

\section{Instrumentation}

The instrumentation used in this study consists of a ground-based all-sky imager and ESR. The all-sky imager uses an electron multiplier charge-coupled device (EMCCD) camera (Hamamatsu, C9100-13) with an imaging resolution of $512 \times 512$ pixels, and it measures emissions at two wavelengths: $557.7 \mathrm{~nm}$ and $630.0 \mathrm{~nm}$. The imager has been operating in Longyearbyen, Norway (geographical latitude $78.1^{\circ} \mathrm{N}$ and longitude $16.0^{\circ} \mathrm{E}$ ) since October 2011 [Taguchi et al., 2012]. During the first observation season, from October 2011 to February 2012, we obtained $630.0 \mathrm{~nm}$ data at $4 \mathrm{~s}$ intervals with an exposure time of $4 \mathrm{~s}$ per image. In the present study, we focused on events that occurred on 27 November 2011, during the first observation season; information after the second season or later has been reported elsewhere [Taguchi et al., 2015a, 2015b]. We note that the imager can clearly detect faint emissions from polar cap patches in this exposure time [Hosokawa et al., 2013a, 2013b, 2016a, 2016b; Sakai et al., 2014]. For ESR, we used data from the $42 \mathrm{~m}$ dish antenna, which was fixed so that its beam was aligned with the magnetic field lines. In the following sections, we compare the plasma data averaged over the $F$ region along the magnetic field lines with the $630.0 \mathrm{~nm}$ aurora intensity data obtained in the same direction.

\section{Observations}

\subsection{Overview of Events Occurring on 27 November 2011}

Figure 1 shows an example of the $630.0 \mathrm{~nm}$ all-sky images. This image was captured at 0747:02 UT, when Longyearbyen was located at approximately 1045 magnetic local time. The white arrow in the figure indicates a mesoscale elongated auroral structure, which is one of the events examined in this study. This aurora is located roughly along the geographical east-west meridian. The black diamond on the image of the aurora structure represents the direction of the ESR beam. As discussed subsequently, the aurora structure moved west-northwestward; at the same time, the ESR beam passed through the moving aurora structure.

This mesoscale aurora is among seven cases investigated in this study. Before providing the detailed characteristics of all of these events, we will provide aurora overviews in a keogram format during a longer interval together with the near-Earth interplanetary magnetic field (IMF) data. Figure 2 shows the north-south keogram reproduced from all-sky images for 0500-0900 UT and the IMF observations by the Geotail spacecraft. The black triangle shown at the bottom of Figure $2 \mathrm{~d}$ indicates the time of the all-sky image data 


\section{AGU Journal of Geophysical Research: Space Physics

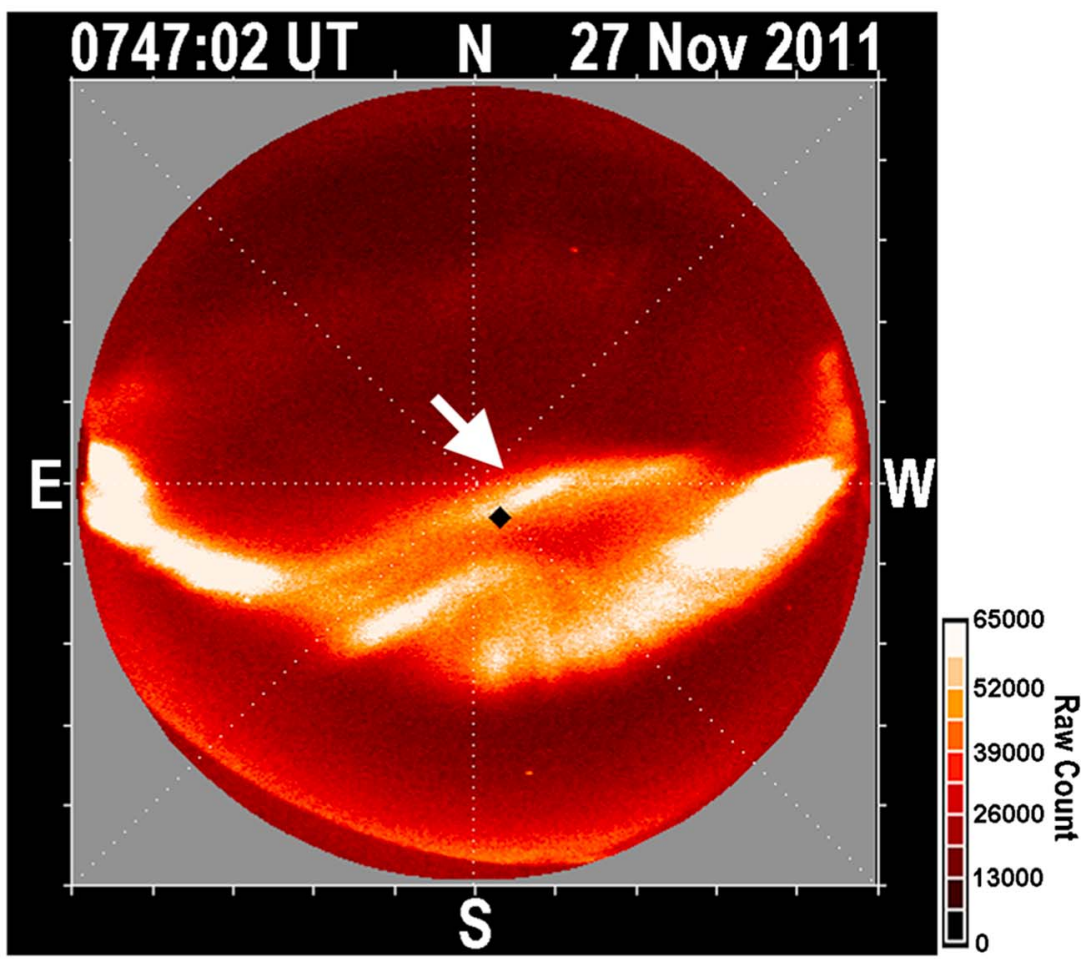

Figure 1. A $630.0 \mathrm{~nm}$ all-sky image taken at 0747:02 UT on 27 November 2011. A white arrow indicates a mesoscale auroral structure, which is one of the events examined in this study. A black diamond represents the direction of the ESR fieldaligned radar beam. N-S and E-W represent the geographical north-south and east-west meridians, respectively.

shown in Figure 1 (0747:02 UT). During an interval from approximately 0600 to 0810 UT, the equatorward boundary of the aurora was located at the south at zenith angles larger than $30^{\circ}$, and many poleward moving aurora features were identified. On that day, the ESR $42 \mathrm{~m}$ radar began observations at $\sim 0702 \mathrm{UT}$. In this study, we focus on the interval of approximately $1 \mathrm{~h}$, from 0702 UT to 0800 UT.

Figures 2a-2c show the $X_{\mathrm{GSM}}, Y_{\mathrm{GSM}}$, and $Z_{\mathrm{GSM}}$ components of IMF data (15 s average) obtained by Geotail, respectively. The Geotail position during this $4 \mathrm{~h}$ interval is $\left(X_{\mathrm{GSE}}, Y_{\mathrm{GSE}}, Z_{\mathrm{GSE}}\right)=(22.7-22.9,9.6-12.4,-3.8$ to $-3.0) R_{E}$. No time lag was considered in the plot. The $Z_{\mathrm{GSM}}$ component, i.e., $B_{Z}$ (Figure $2 \mathrm{c}$ ), became negative after $\sim 0605 \mathrm{UT}$, and the negative $B_{Z}$ continued until $\sim 0800$ UT. A comparison of Figure $2 \mathrm{c}$ with Figure $2 \mathrm{~d}$ reveals that the equatorward boundary of the aurora was situated to the south in accordance with the negative $B_{Z}$ intervals, which reaffirms that the time lag from the Geotail to the cusp need not be introduced in this interval.

The $Y_{\mathrm{GSM}}$ component, $B_{\mathrm{Y}}$ (Figure $2 \mathrm{~b}$ ), had small magnitudes and predominantly negative values during 0500 0600 UT. Later, $B_{Y}$ became positive. The $X_{\mathrm{GSM}}$ component of the IMF, $B_{X}$ (Figure 2a), was positive except for a brief interval at nearly 0600 UT. During the plotted interval, the Wind spacecraft was also observing the IMF and solar wind at a distant upstream location. In the Wind IMF data, which are obtained from the NASA CDAWeb service, negative $B_{Z}$ intensification accompanied with the change of the $B_{Y}$ sign from negative to positive is evident at 0517 UT, which is $48 \mathrm{~min}$ ( $=0605$ UT - 0517 UT) before the similar change at Geotail. The Wind solar wind speed during $2 \mathrm{~h}$ after 0517 UT was roughly stable at $350 \mathrm{~km} \mathrm{~s}^{-1}$. The proton density was between $\sim 7 \mathrm{~cm}^{-3}$ and $\sim 12 \mathrm{~cm}^{-3}$ for that period.

\subsection{Simultaneous Observations From All-Sky Imager and ESR}

Figure 3 shows the $30 \mathrm{~s}$ integrated electron density $\left(N_{e}\right)$ and electron temperature $\left(T_{e}\right)$ measured by ESR and the $4 \mathrm{~s}$ resolution aurora intensity $(630.0 \mathrm{~nm})$ obtained in the direction of the radar beam during 0700 0800 UT. Figures $3 \mathrm{a}$ and $3 \mathrm{~b}$ represent the height profiles of $N_{e}$ and $T_{e}$, respectively, and in Figure $3 c$, the auroral intensity (black dot) is compared with $T_{e}$ (red line). $T_{e}$ in Figure $3 c$ represents the average value 


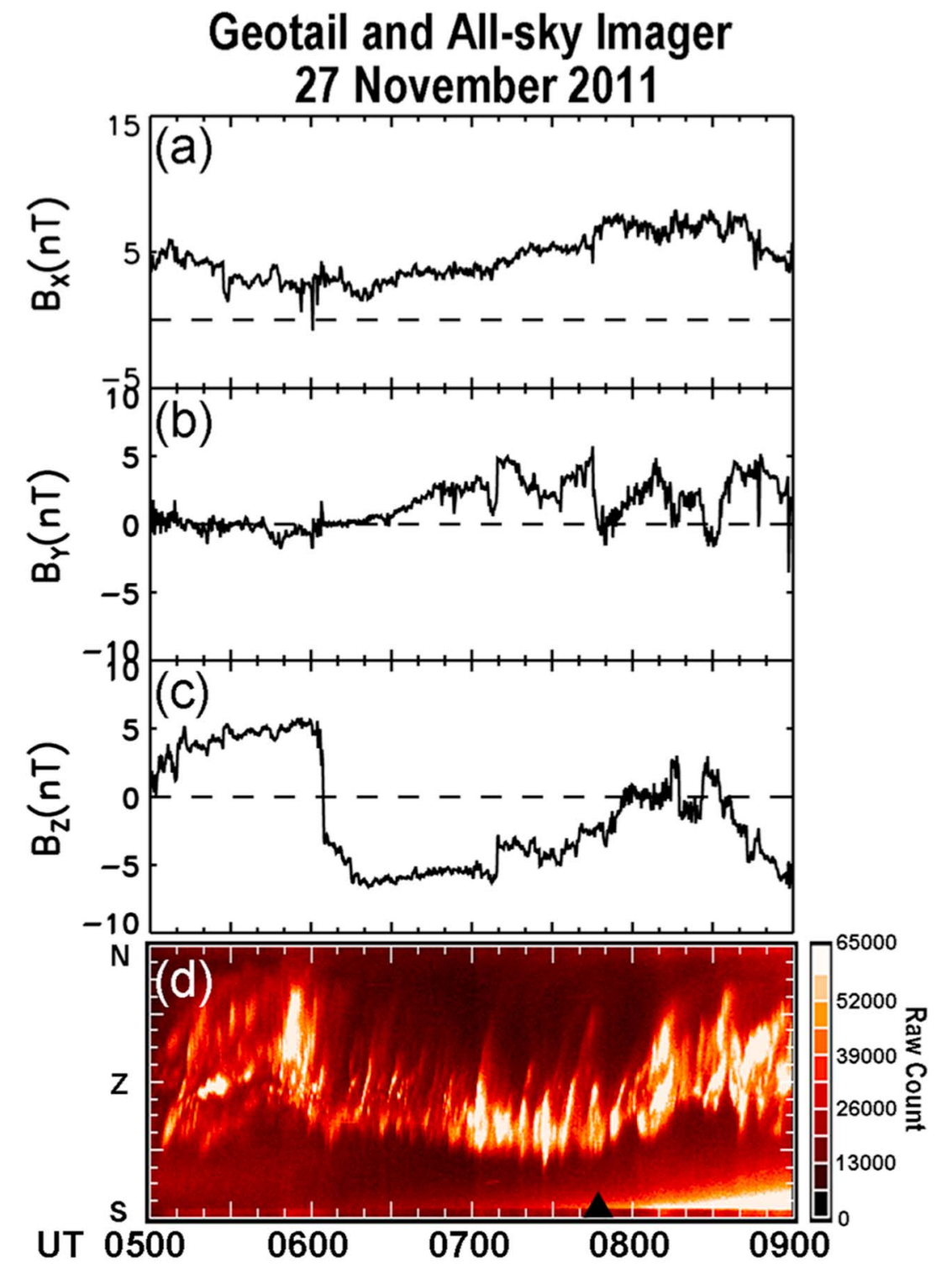

Figure 2. IMF observed by the Geotail spacecraft and $630.0 \mathrm{~nm}$ auroral intensity in the north-south keogram for 0500-0900 UT on 27 November 2011. The (a) $X$, (b) $Y$, and (c) $Z$ components of the IMF in the GSM coordinate are plotted. (d) The keogram is reproduced from all-sky images. The black triangle shown at the bottom of Figure $2 \mathrm{~d}$ indicates the time of the all-sky image data shown in Figure 1 (0747:02 UT).

from altitudes of $225-375 \mathrm{~km}$. The error bars of this plot represent the standard deviation. The red horizontal line indicates $T_{e}=2500 \mathrm{~K}$ for reference. Figure $3 \mathrm{~d}$ shows the average $N_{e}$ values from altitudes of $225 \mathrm{~km}$ to $375 \mathrm{~km}$ (red) together with those from altitudes of $400 \mathrm{~km}$ to $500 \mathrm{~km}$ (blue). The error bars represent the standard deviation. The black dotted line indicates $N_{e}=3 \times 10^{11} \mathrm{~m}^{-3}$ for reference. The black triangle in each panel represents the time (i.e., 0747:02 UT) at which the all-sky image shown in Figure 1 was captured. We focused on the isolated auroral enhancements. In Figures $3 c$ and $3 d$, the vertical solid line represents the start of the auroral enhancements. We determined the start as the time at which an increase occurred after a "quiet" interval that is longer than $4 \mathrm{~min}(240 \mathrm{~s})$. Specifically, the auroral intensity exceeded the average for the preceding $240 \mathrm{~s}$ by at least $150 \mathrm{R}$, and the average from the following $16 \mathrm{~s}$ exceeded that auroral intensity by at least $150 \mathrm{R}$. We required an auroral intensity increase of more than $300 \mathrm{R}$ for $20(=4+16) \mathrm{s}$.

Events 1-7 began at 0702:05, 0714:24, 0719:29, 0727:10, 0736:27, 0744:51, and 0755:07 UT, respectively. The aurora shown in Figure 1 is referred to as Event 6. In Event 6, as well as in Events 1, 5, and 7, the aurora 

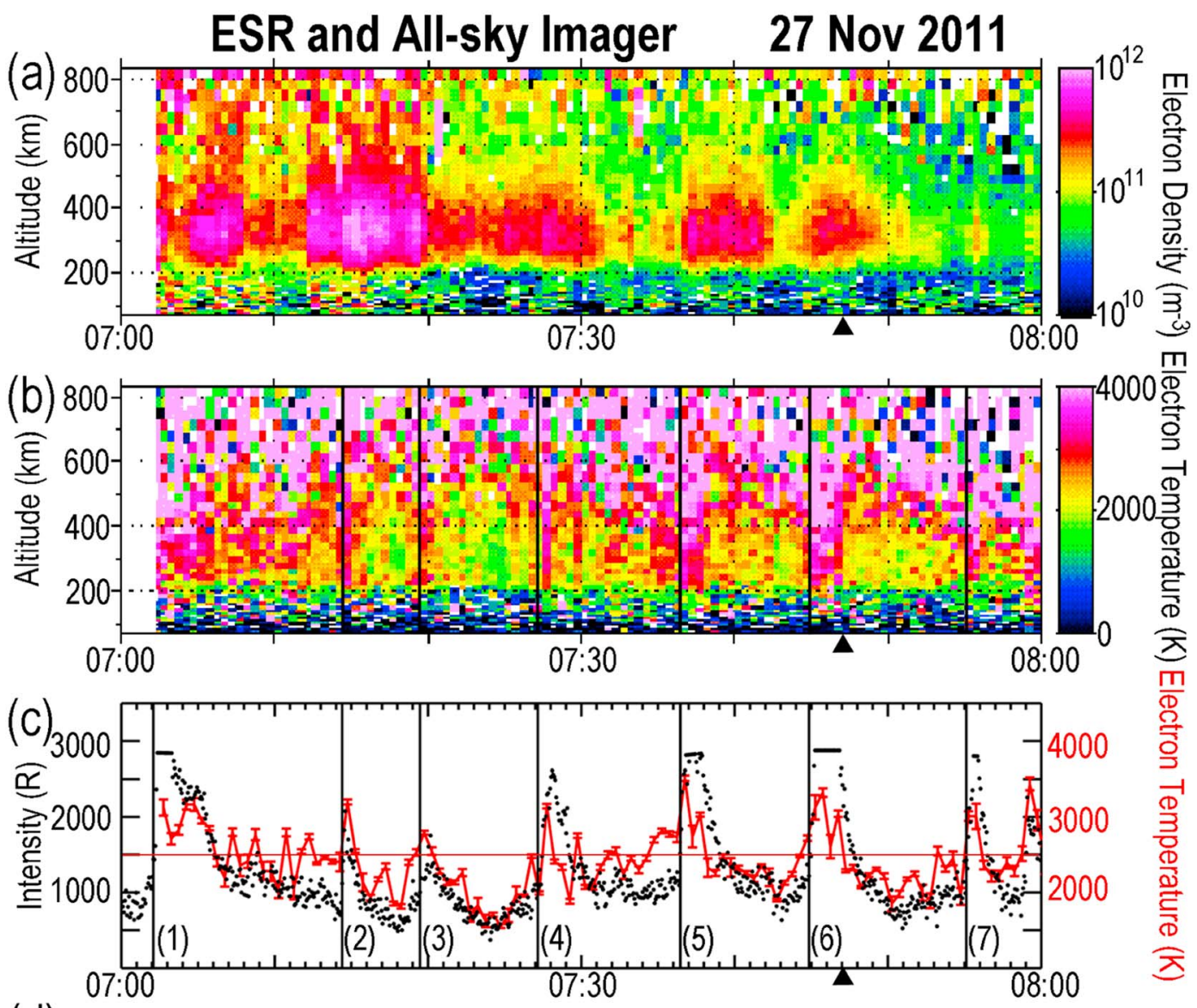

(d)

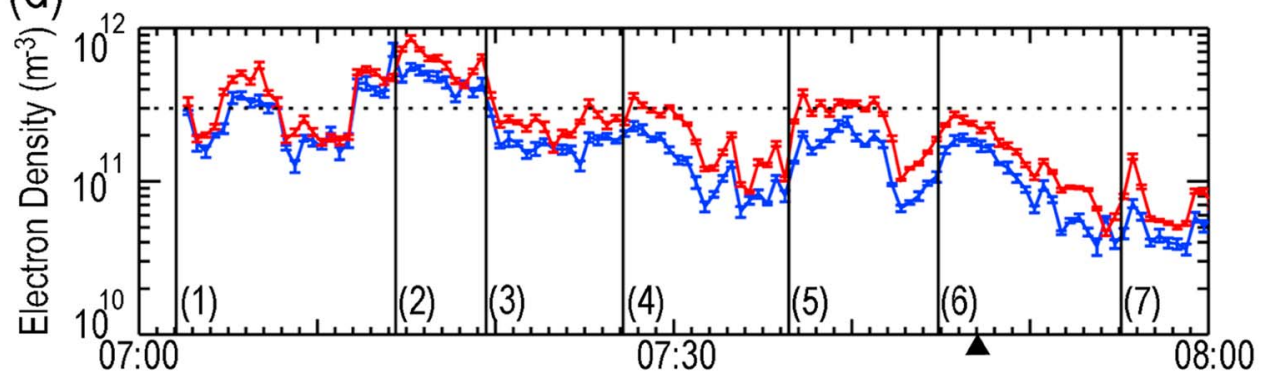

Figure 3. Electron density and electron temperature measured by ESR, and aurora intensity $(630 \mathrm{~nm})$ obtained in the direction of the ESR beam during 0700-0800 UT. The height profiles of (a) electron density and (b) electron temperature are presented. (c) The auroral intensity (black dot) and its comparison with the average $T_{e}$ from a section $150 \mathrm{~km}$ in width centered at $300 \mathrm{~km}$; i.e., $225-375 \mathrm{~km}$ is shown. The red horizontal line indicates $T_{e}=2500 \mathrm{~K}$. (d) The average values of electron density from altitudes of $225-375 \mathrm{~km}$ (red) and those from altitudes of $400-500 \mathrm{~km}$ (blue) are plotted. The horizontal dotted line represents a reference value of $3 \times 10^{11} \mathrm{~m}^{-3}$. The seven vertical lines, shown as (1) to (7) in Figures $3 \mathrm{c}$ and $3 \mathrm{~d}$ represent the start of the auroral enhancements. Those times are also shown in Figure $3 \mathrm{~b}$ with the vertical lines except for (1). The black triangles in Figures 3a-3d represent the time (i.e., 0747:02 UT) when the all-sky image shown in Figure 1 was captured.

intensities (black dots) showed unusually constant features for a brief interval. These features mean simply that the aurora intensity exceeded the upper limit of the dynamic range of the EMCCD camera in the observation mode used in that season. For all events except for Event 1, the start time is also shown in Figure $3 b$, as represented by the vertical line.

Figure $3 \mathrm{~b}$ shows that at the start of Event 6 (second vertical line from the right) the ESR $T_{e}$ at altitudes near $300 \mathrm{~km}$ was sharply enhanced (reddish color, roughly $3000 \mathrm{~K}$ ). Similar features were observed in Events 2-5 and 7, although for Event 5, the $T_{e}$ enhancements appeared to start gradually a few minutes earlier than 
Table 1. Auroral Intensity at the Time of $T_{e}$ Drop

\begin{tabular}{llcc} 
Event & UT for $T_{e}<2500 \mathrm{~K}$ & $I_{\text {MAX }}(\mathrm{R})$ & $I_{\text {MIN }}(\mathrm{R})$ \\
\hline 1 & $0706: 00-0706: 30$ & 1700 & 1300 \\
2 & $0715: 30-0716: 00$ & 1000 & 800 \\
3 & $0720: 30-0721: 00$ & 1300 & 1000 \\
4 & $0728: 00-0728: 30$ & 2600 & 2000 \\
5 & $0738: 00-0738: 30$ & 2400 & 1800 \\
6 & $0747: 00-0747: 30$ & 2400 & 1700 \\
7 & $0756: 00-0756: 30$ & 2400 & 1500 \\
\hline
\end{tabular}
explained by cusp electron precipitation. We obtained the average $T_{e}$ from a section $150 \mathrm{~km}$ in width centered at $300 \mathrm{~km}$, i.e., $225-375 \mathrm{~km}$. The temporal variations are shown in Figure 3c.

Figure $3 \mathrm{c}$ shows that at the start of Event 6 the ESR $T_{e}$ was enhanced and exceeded $2500 \mathrm{~K}$. Between 0745:30 and 0746:00 UT, $T_{e}$ reached its maximum value of approximately $3300 \mathrm{~K}$. In this $30 \mathrm{~s}$ interval, the auroral intensity was also strong, although its actual value was not measured. In all events except for Event $3, T_{e}$ exceeded $3000 \mathrm{~K}$ (Figure 3c), and the auroral intensity was also relatively strong (>2000 R) at each $T_{e}$ maximum.

We now examine the relationship between the drop in $T_{e}$ and the decrease in auroral intensity. Figure $3 c$ shows that for Event 6, $T_{e}$ dropped below $2500 \mathrm{~K}$ between 0747:00 and 0747:30 UT. This drop is also clearly shown in Figure $3 \mathrm{~b}$ as a sharp change in $T_{e}$ at altitudes near $300 \mathrm{~km}$ (reddish color to yellow color). The auroral emission decreased during this $30 \mathrm{~s}$ interval but still had adequate intensities at $\sim 1700 \mathrm{R}$ to $\sim 2400 \mathrm{R}$. These values are well above the background level. In Table 1, we summarized the auroral intensities observed when $T_{e}$ dropped below $2500 \mathrm{~K}$ for all events. $I_{\mathrm{MAX}}$ and $I_{\mathrm{MIN}}$ in the table represent the maximum and minimum auroral intensity during the $30 \mathrm{~s}$ interval. For Events $4-7, I_{\text {MAX }}$ was $2400 \mathrm{R}$ or more, and $I_{\text {MIN }}$ was at least $1500 \mathrm{R}$, indicating that the auroral intensities were well above the background level. That is, the auroral emissions continued with adequate intensities even after $T_{e}$ dropped below $2500 \mathrm{~K}$. For the three other events (Events 1-3), the auroral intensities were relatively weak.

In Figure 3d the average $N_{e}$ values from altitudes of $225 \mathrm{~km}$ to $375 \mathrm{~km}$ (red) show that the $N_{e}$ variation at the start time differed among six events. In Event $2 N_{e}$ increased to a relatively high value $\left(\sim 9 \times 10^{11} \mathrm{~m}^{-3}\right)$, whereas $N_{e}$ decreased for Event 3. In Event 4, the $N_{e}$ increase was not very prominent but that for Event 5 and Event 7 was clear. For Event 5 , the enhanced $N_{e}$ continued for a much longer time than the enhanced $T_{e}$ (Figure 3c). For Event 6, the $N_{e}$ increase was very gradual and did not reach $3 \times 10^{11} \mathrm{~m}^{-3}$. These inconsistencies suggest that the dominant $N_{e}$ increase does not have a common source for the auroral emission intensification, i.e., electron precipitation except for Event 7. For Event 7 modest $N_{e}$ enhancements correlated with enhancements of both $T_{e}$ and the auroral intensity. $N_{e}$ peaked at approximately $1.5 \times 10^{11} \mathrm{~m}^{-3}$ during 0755:30-0756:00 UT in accordance with the $T_{e}$ enhancements. This modest increase in $N_{e}$ may have been caused by the ionization due to electron precipitation.

The most enhanced $N_{e}$ occurred between Events 2 and 3. This interval clearly includes the period in which both $T_{e}$ and the auroral intensity were very low ( 0716 to $\left.\sim 0718 \mathrm{UT}\right)$. For Event 5, relatively high $N_{e}$ continued to $\sim 0742 \mathrm{UT}$; the latter half of that enhanced $N_{e}$ interval included the period in which both $T_{e}$ and the auroral intensity were low. In general, the high $N_{e}$ and low $T_{e}$ observed in the cusp indicate that the plasma was transported to that region without being produced by an electron impact. Because IMF $B_{Z}$ was southward (Figure 2), it is inferred that the high $N_{e}$ and low $T_{e}$ plasma arrived at the cusp from its equatorward side [e.g., Lockwood and Carlson, 1992]. In the present event, the $N_{e}$ enhancements would not be a good indicator of the electron precipitation, as is the event presented by Doe et al. [2001].

Red line emissions can also be caused by thermal electron gas of sufficiently high temperature [e.g., Rees and Roble, 1975; Kozyra et al., 1990; Lockwood et al., 1993; Carlson et al., 2013]. Those studies indicated that emission owing to thermal excitation is relatively strong when $T_{e}$ is elevated to typically $>3000 \mathrm{~K}$ and that $N_{e}$ is relatively high $\left(>3 \times 10^{11} \mathrm{~m}^{-3}\right)$. Figures $3 \mathrm{c}$ and $3 \mathrm{~d}$ (red lines) show that $T_{e}$ and $N_{e}$ at altitudes of $\sim 300 \mathrm{~km}$ exceeded $3000 \mathrm{~K}$ and $3 \times 10^{11} \mathrm{~m}^{-3}$, respectively, only for three brief periods for Events 1, 2, and 4. Figure 3 b shows that $T_{e}$ often exceeded $3000 \mathrm{~K}$ at altitudes of $400-500 \mathrm{~km}$, which is thought to be the dominant source for thermal excitation [Lockwood et al., 1993; Carlson et al., 2013]. However, Figure 3d indicates that 


\section{AGU Journal of Geophysical Research: Space Physics

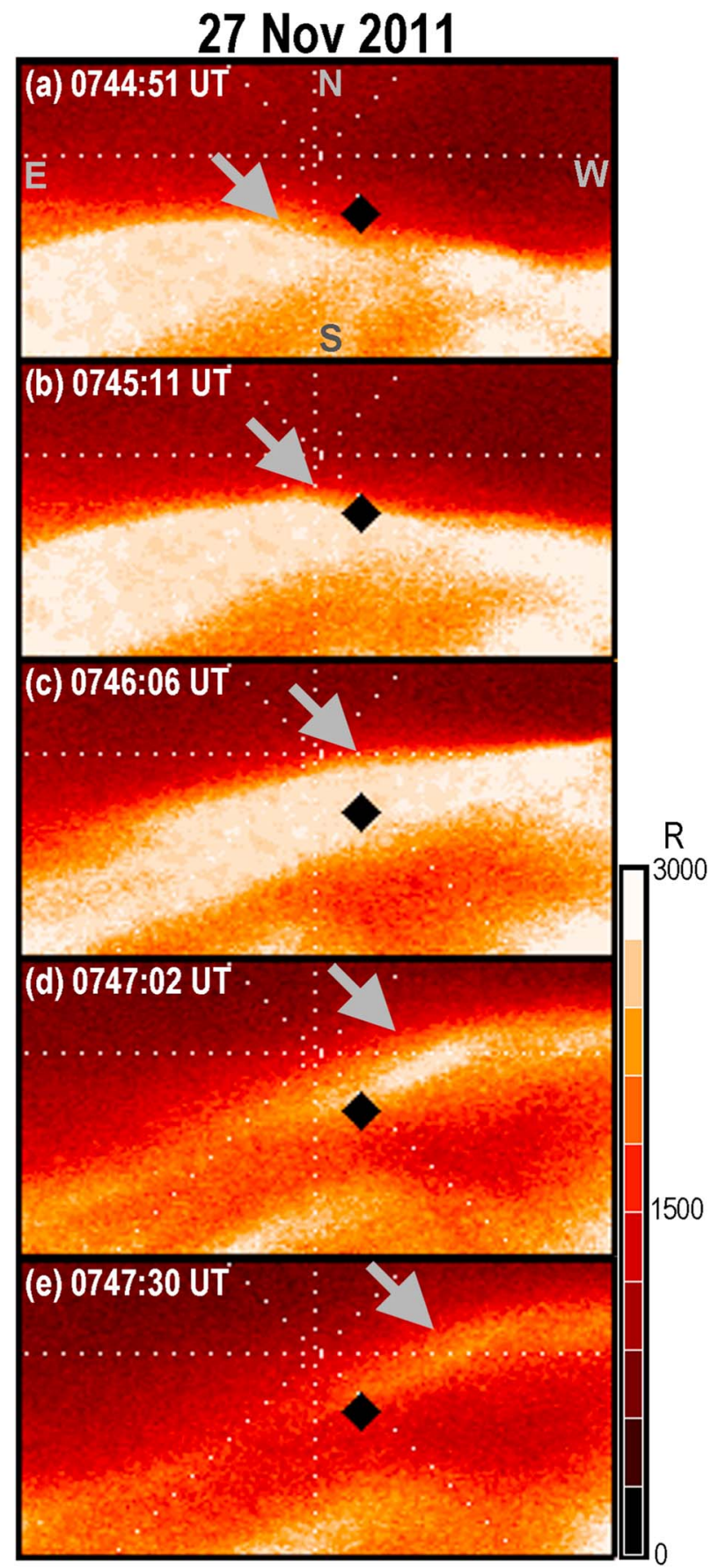

Figure 4. Auroral images at (a-e) five times during Event 6 , representing that a mesoscale auroral structure was passing through the radar's field of view (black diamond). The gray arrow indicates the moving auroral structure. $\mathrm{N}-\mathrm{S}$ and $\mathrm{E}-\mathrm{W}$ in Figure 4a represent the geographical north-south and east-west meridians, respectively.
$N_{e}$ at those altitudes (blue line) is below $3 \times 10^{11} \mathrm{~m}^{-3}$ except for two brief intervals after Event 1 and between Events 2 and 3. During those brief intervals, the red line emission was not markedly high. Relatively strong red line emissions occurred in Events 5 and 6. For the $1 \mathrm{~h}$ interval investigated in this study, the contribution to the red line intensity from the thermal excitation was very small.

\subsection{Motion of the Aurora in Seven Events}

In Figure 4, five close-up auroral images around the radar's field of view are shown for Event 6 . The black diamond in Figures $4 a-4 e$ indicates the direction of the radar's field of view. The auroral image in Figure $4 a$ was obtained at 0744:51 UT, i.e., at the start of the auroral enhancements, as defined in Figure 3c. At the bottom left of this image, a relatively strong emission region is apparent, the northern boundary of which is indicated by the gray arrow. This auroral structure moved westnorthwestward, and at 0745:11 UT (Figure 4b), the front part of the strong emission region intersected the radar's field of view. The westnorthwestward motion in the northern cusp is consistent with IMF $B_{Y}$ positive (Figure $2 b$ ).

At 0746:06 UT (Figure 4c), the radar's field of view passed through the central part of the auroral structure. Figure $4 \mathrm{~d}$ is the first image obtained during the $30 \mathrm{~s}$ interval (0747:000747:30 UT in Table 1) in which the ESR $T_{e}$ dropped below $2500 \mathrm{~K}$. Such a low $T_{e}$ implies the absence of significant electron precipitation in the direction of the radar's field of view. The radar's field of view passed through the rear part of the auroral structure at that time. Figure $4 \mathrm{e}$ shows the last image captured during the above mentioned $30 \mathrm{~s}$ interval (0747:30 UT). The radar's field of view was still passing through the rear part of the diminishing auroral structure. From these five images, the variations of the auroral intensity and $T_{e}$, shown in Figures $3 \mathrm{~b}$ and $3 \mathrm{c}$, have been inferred to be directly associated with the passage of the mesoscale auroral structure. Animation S1 in the supporting information shows the motion of the aurora for a longer period. 


\section{AGU Journal of Geophysical Research: Space Physics}

\section{Nov 2011}

Event 1

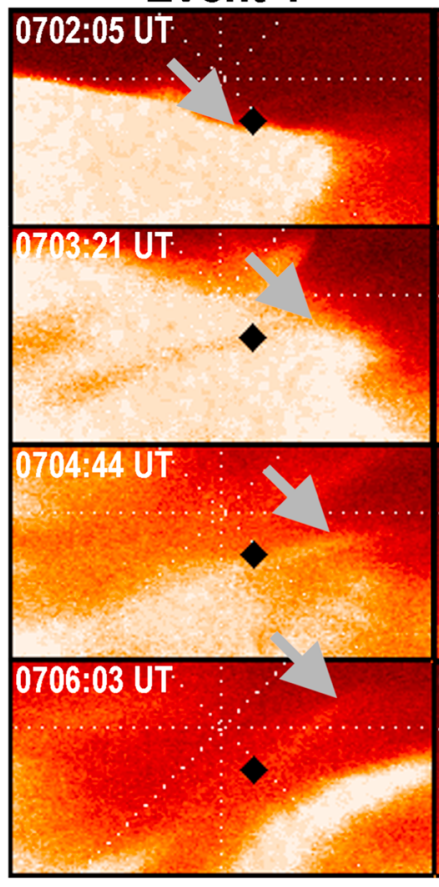

Event 4

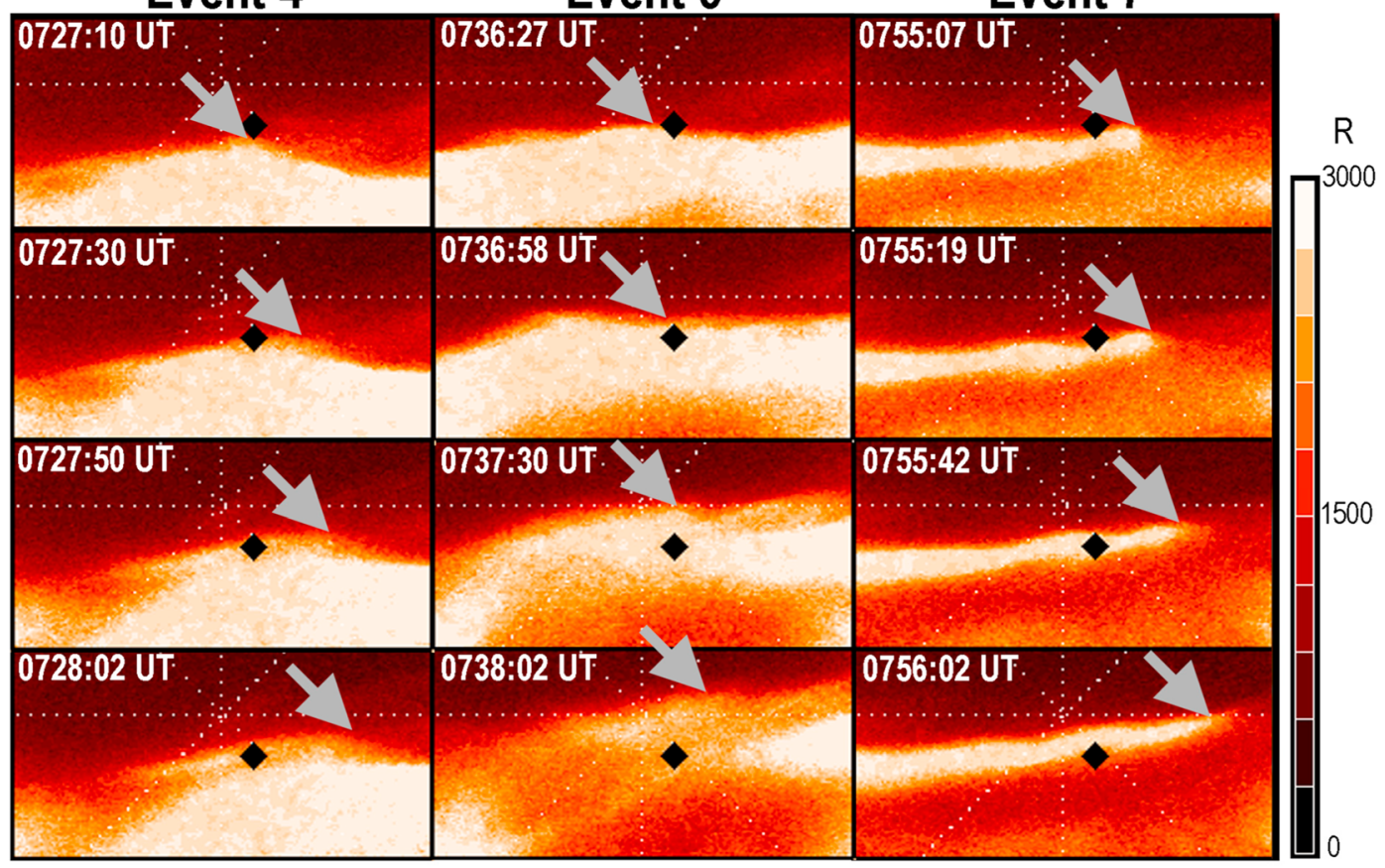

Figure 5. Motion of the auroral structure for six events, shown in the same format as that in Figure 4 except that each event has four images.

Four close-up auroral images for each of the other six events are shown in Figure 5. The format of each image is the same as that in Figure 4. The topmost image for each event was obtained at the defined start time of the auroral enhancements (time for the vertical lines in Figure 3c). The images in the second and third panels in each event indicate two situations that occurred after the start of auroral enhancements and before the ESR $T_{e}$ drop to $<2500 \mathrm{~K}$. The image obtained immediately after the ESR $T_{e}$ drop to $<2500 \mathrm{~K}$ is shown at the bottom of the image stack for each event. 
The top image for Event 1 shows that the strong aurora (gray arrow) existed immediately on the equatorward side of the radar's field of view at that time. A comparison of the top and the second images (0702:05 and 0703:21 UT) reveals that the start of the auroral enhancements in the radar beam direction was caused by the expansion and subsequent motion of the aurora located on the equatorward side. Figure $3 \mathrm{c}$ shows that at 0703:21 UT the auroral intensity in the radar beam direction was in its decreasing phase. From the image taken at 0703:21 UT (Figure 5), it is inferred that the ESR's beam was passing through the weak intensity region that was roughly aligned west-northwestward (gray arrow). Then, when the weakening of the auroral intensity was prominent on the northern side, such that at 0704:44 UT the radar's field of view was near the edge of the narrow aurora extending westward (gray arrow). This part of auroral structure moved northward until 0706:03 UT, when the radar's field of view was near the trailing edge of the diminishing aurora. From these images, we can infer that the auroral motion in the radar's field of view during Event 1 was complicated and that the variations in the auroral intensity in the direction of the radar's field of view (Figure 3c) are not the result of simple motion of a mesoscale auroral structure.

The four images (0714:24-0715:32 UT) for Event 2 show that the motion of the narrow auroral structure (indicated by the gray arrow) is associated with the auroral intensity in the radar's field of view. The auroral structure moved in the west-northwest direction, which is similar to the auroral structure for Event 6 (Figure 4). In the case of Event 3, the manner in which the auroral structure passed through the radar's field of view differed significantly from that shown in Event 6 . A comparison of the topmost and the second images (0719:29 and 0719:46 UT) reveals that the start of the auroral enhancements in the radar beam direction was caused by the northward expansion of the aurora structure (gray arrow). This auroral structure gradually diminished without moving significantly, as shown in the bottom two images (0720:02 and 0720:30 UT).

The situation in Event 4 is similar to that in Event 6. In the topmost image (0727:10 UT), the angulated portion of the auroral structure is indicated by the gray arrow. At 0727:30 UT (second image), this structure shifted west-northwestward. Subsequently, as shown in the images captured at 0727:50 and 0728:02 UT, the auroral structure moved farther west-northwestward. The radar's field of view in this event cut across the auroral structure in a manner similar to that in Event 6.

The motion of the auroral structure in Event 5 is also similar to that in Event 6, even though the motion in the initial stage (images taken at 0736:27 and 0736:58 UT) was not clearly identified due to very strong emissions. At 0736:27 UT the strong aurora (gray arrow) began to intersect the radar's field of view. In the third image (0737:30 UT) the angulated portion of the auroral structure, which is the front edge of the moving auroral structure, is indicated by the gray arrow. A comparison of the images captured at 0737:30 UT and 0738:02 UT reveals that the auroral structure moved west-northwestward.

The images for Event 7 show that the narrow, long auroral structure was in motion. The images captured at 0755:07 and 0755:19 UT show that the initial increase in the auroral intensity in the radar's field of view (Figure 3c) is associated with the motion of the auroral structure. At 0755:42 UT, the direction of the radar beam passed through the central part of the auroral structure. At 0756:02 UT, when the ESR $T_{e}$ was $<2500 \mathrm{~K}$, the radar's field of view was still passing through the auroral emission region.

Figures 4 and 5 indicate that in Events 2, and 4-7 among the defined seven events the mesoscale moving auroral structure passed through the direction of the radar beam. As described in Figure $3 c$, in these events, except for Event 2, the auroral emission sustained significant intensities even after the ESR $T_{e}$ dropped. These common features are direct results of the motion of the mesoscale cusp auroral structure in the radar's field of view.

\section{Discussion}

\subsection{Motion of Aurora and $T_{e}$ Variations}

In Figure 6 we illustrated a possible relationship between the motion of the auroral structure and the $T_{e}$ variations, which is consistent with the common features of Events 4-7. The elongated shape shown at the top of the figure is the auroral emission region. The hatched region inside represents the $T_{e}$ enhancement region, which was produced by electron precipitation. We assumed that the electron precipitation region moved in the direction indicated by the gray arrow. The small solid circle represents the relative position of the direction of the radar beam to the auroral structure at each of four different times of $t_{1}, t_{2}, t_{3}$, and $t_{4}$. 


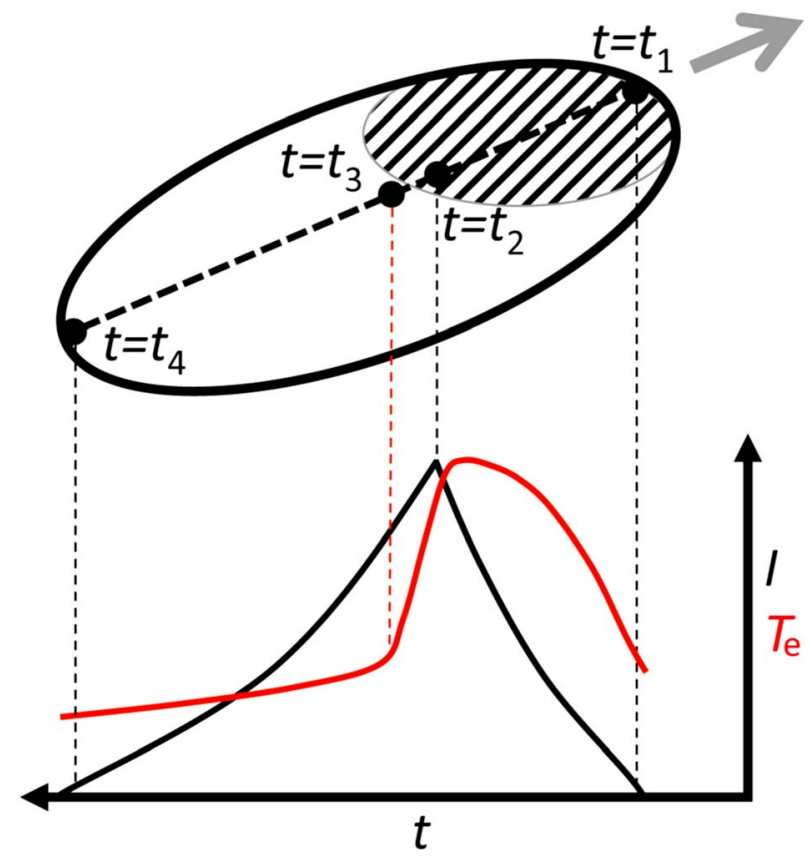

Figure 6. Schematic illustration showing a possible relation between the motion of the auroral structure and ESR $T_{e}$ variations. An elongated shape shown at the top is the auroral emission region. The hatched region inside the auroral emission region represents the $T_{e}$ enhancement region, which is produced by electron precipitation. The gray arrow indicates the direction in which the electron precipitation is moving. The small solid circle on the dotted line represents the relative position of the direction of the ESR beam to the auroral structure at each of four different times, $t=t_{1}, t_{2}, t_{3}$, and $t_{4}$. The bottom illustration represents the variations in the auroral intensity I (black) and the ESR $T_{e}$ (red).

stantial electron precipitation at this point, we have determined the region of electron precipitation (shad region) so as to not include this position $\left(t=t_{3}\right)$ in the electron precipitation region. Admittedly, the $T_{e}$ enhancements may be delayed from the electron precipitation, but this delay is usually $<30 \mathrm{~s}$, which is the integration time of the ESR data. The numerical model by Sadler et al. [2012] shows that the electron temperatures are enhanced significantly about $20 \mathrm{~s}$ after the electron precipitation. The position labeled $t_{4}$ shows the case in which the auroral intensity diminished sufficiently and was close to the background level.

\subsection{Equation of Continuity of $O\left({ }^{1} D\right)$ in the Moving Cusp Aurora}

To better understand the relationship summarized in Figure 6, we considered the volume emission rate for the auroral intensity. The auroral intensity / can be expressed as the integral of the volume emission rate $\varepsilon$ along the line of sight:

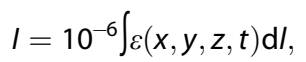

where $\varepsilon$ represents the three-dimensional distribution of the volume emission rate for the $630.0 \mathrm{~nm}$ emission, expressed in $\mathrm{cm}^{-3} \mathrm{~s}^{-1} ; \mathrm{d} /$ is the line element in centimeters; $/$ is the intensity expressed in Rayleigh (R, $10^{6}$ photons $\left.\mathrm{cm}^{-2} \mathrm{~s}^{-1}\right)$; and $\varepsilon$ is a function of time $t$ and spatial parameters $x, y$, and $z$. We analyzed the auroral intensity data obtained in the direction of the radar beam, i.e., the elevation angle of $82^{\circ}$ (Figure $3 c$ ). Because this elevation angle is approximately vertical upward, the integral along the line in (1) can be approximated as the integral along the vertical upward line. We then considered the vertical profiles, i.e., the altitude profiles of $\varepsilon$, below.

The model proposed by Rees and Roble [1986] indicates that the altitude profile of the normalized volume emission rate of the $630.0 \mathrm{~nm}$ radiation for incident Maxwellian electron-energy spectra with a characteristic energy of $100 \mathrm{eV}$ peaks at an altitude of approximately $240 \mathrm{~km}$. A recent study by Taguchi et al. [2015b] shows 
that the electron precipitation features at approximately $100 \mathrm{eV}$ are very similar between the moving cusp aurora in the initial stage and that in the final stage. It is reasonable to assume that the features of the electron precipitation do not change significantly at least during a brief period of a few minutes while the radar beam passes through the entire structure of the moving cusp aurora. On the basis of these two studies, we suggest that the constant distribution of the volume emission rate, which peaks at a certain altitude, exists for a brief period of observation.

The altitude profiles of $\varepsilon$ decrease rapidly below and above the maximum altitude [Rees and Roble, 1986] even though its decrease is more rapid at lower altitudes owing to the effect of collisional quenching. For this type of distribution, the maximum value can be almost proportional to the integral of the function. For example, when we take a Gaussian function form, i.e., $\varepsilon=\varepsilon_{M} \exp \left(-\left(z-z_{M}\right)^{2} /(2 h)^{2}\right)$, where $z$ is the altitude, $z_{M}$ is the altitude for the maximum $\varepsilon_{M}$, and $h$ is the profile width of the Gaussian function, the integral of this function from $z=0$ to $z=\infty$ gives $\sqrt{\pi} \varepsilon_{M} h$. This shows that $\varepsilon_{M}$, i.e., the maximum value of $\varepsilon$, is exactly proportional to the integral value. Under these circumstances, the auroral intensity can be regarded as being roughly proportional to the maximum value of $\varepsilon$ and therefore to the number density of $O\left({ }^{1} D\right)$ at the altitude with the maximum $\varepsilon$; i.e., $I \propto n_{M}$, where $I$ is the auroral intensity and $n_{M}$ represents the number density of $O\left({ }^{1} D\right)$ at the altitude at which the maximum $\varepsilon$ occurs. We then considered the continuity equation for $n_{M}$. In the following continuity equation,

$$
\frac{\partial n_{M}}{\partial t}+\nabla \cdot\left(n_{M} \boldsymbol{v}\right)=P-L
$$

$\boldsymbol{v}$ represents the velocity of $O\left({ }^{1} D\right)$; $P$ represents the production rate at altitude $z_{M}$ for the maximum $\varepsilon$, which is associated with electron precipitation; and $L$ is the loss rate at $z=z_{M}$. This loss rate can be expressed by $n_{M} / \tau_{M}$, where $\tau_{M}$ is the lifetime of $O\left({ }^{1} D\right)$ at that altitude. In (2), $P$, which is related to the motion of the electron precipitation region, might be expressed by an appropriate function of spatial parameters $x$ and $y$ in the horizontal plane and time $t$. However, we rewrote (2) as the following equation to describe the temporal variations at a fixed position $(x, y, z)=\left(x_{0}, y_{0}, z_{M}\right)$ to explain the temporal variations obtained in Figure $3 c$ :

$$
\begin{aligned}
\frac{\partial n_{M}\left(x_{0}, y_{0}, z_{M}, t\right)}{\partial t}+\frac{n_{M}\left(x_{0}, y_{0}, z_{M}, t\right)}{\tau_{M}} & \\
=P\left(x_{0}, y_{0}, z_{M}, t\right)-\left[\nabla \cdot\left(n_{M}(x, y, z, t) \boldsymbol{v}(x, y, z, t)\right)\right]_{x} & =x_{0} \\
y & =y_{0} \\
z & =z_{M}
\end{aligned}
$$

The production rate at the fixed position, $P\left(x_{0}, y_{0}, z_{M}, t\right)$, should have significant values only during the interval in which the region of electron precipitation passes through $(x, y)=\left(x_{0}, y_{0}\right)$; this value should be zero before and after the interval. On the other hand, the $\nabla \cdot(n \mathbf{v})$ term, i.e., the second term on the right-hand side, is a nonzero term for a longer period than that of the nonzero interval of $P$ because the velocity $\boldsymbol{v}$ of the neutral $\mathrm{O}\left({ }^{1} D\right)$ is driven in a region larger than that of the electron precipitation. The electron precipitation responsible for the moving cusp aurora is accompanied by a twin-vortex plasma flow [e.g., Southwood, 1987; Oksavik et al., 2004; Taguchi et al., 2015a]. Specifically, intense electron precipitation occurs in one cell of the twin vortex [Oksavik et al., 2004]. The velocity $\boldsymbol{v}$ of the neutral $O\left({ }^{1} D\right)$, which is driven by the plasma flow, is collocated roughly to the twin-vortex plasma flow. This indicates that the region in which the $\nabla \cdot(n \mathbf{v})$ term has nonzero values is larger than the electron precipitation region corresponding to one cell in the twin vortex.

Despite the fact that the $\nabla \cdot(n \mathbf{v})$ term may have nonzero values in a longer period than the nonzero interval of $P\left(x_{0}, y_{0}, z_{M}, t\right)$, the former is without doubt the secondary effect as compared with $P\left(x_{0}, y_{0}, z_{M}, t\right)$, which is the main source of the aurora. In the equations below, we assumed that the sum of the two terms on the righthand side in (3) is approximately constant during the period in which the region of electron precipitation is passing through $(x, y)=\left(x_{0}, y_{0}\right)$ and that the sum is zero before and after that period. Taking the nonzero interval as $t=0$ to $t=\tau_{P}$ and denoting the constant value as $P_{0}$, (3) can be expressed as

$$
\frac{\partial n_{M}(t)}{\partial t}+\frac{n_{M}(t)}{\tau_{M}}=\left\{\begin{array}{cc}
P_{0} & \left(0 \leq t \leq \tau_{P}\right) \\
0 & (\text { otherwise })
\end{array} .\right.
$$

These equations can be analytically solved; and the solution for $0 \leq t$ is 


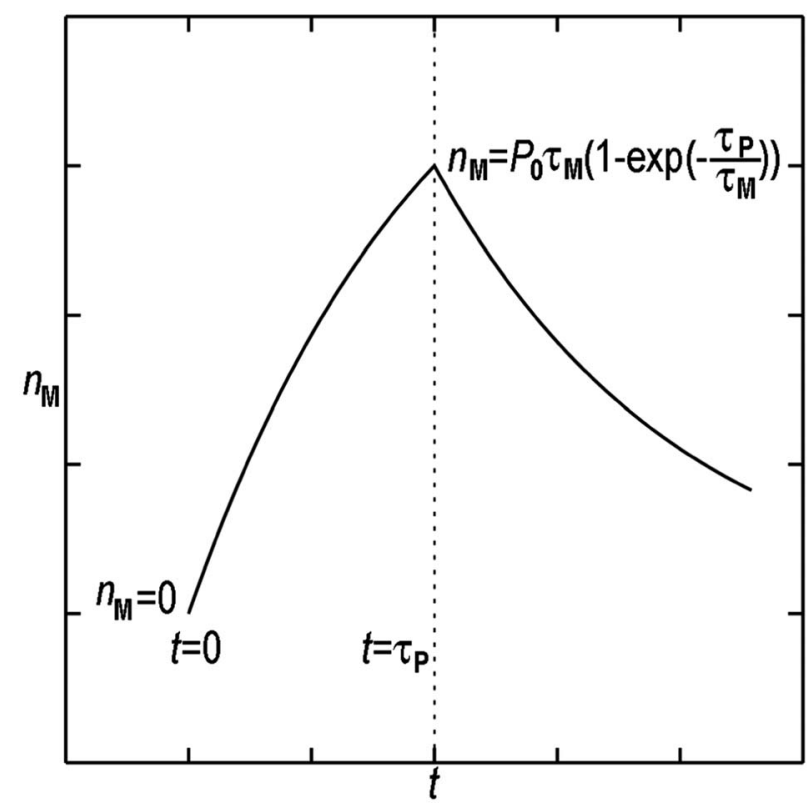

Figure 7. General profiles of equations (5) and (6) for $n_{M}$ in an arbitrary unit. The $n_{M}$ variation takes its maximum at $t=\tau_{P}$.

$$
\begin{gathered}
n_{M}(t)=P_{0} \tau_{M}\left(1-\exp \left(-\frac{t}{\tau_{M}}\right)\right) \quad 0 \leq t \leq \tau_{p} \\
n_{M}(t)=P_{0} \tau_{M}\left(\exp \left(-\frac{t-\tau_{p}}{\tau_{M}}\right)-\exp \left(-\frac{t}{\tau_{M}}\right)\right) \tau_{p}<t
\end{gathered}
$$

In Figure 7, we illustrate the general profiles of (5) and (6) in an arbitrary unit. After $t=0, n_{M}$ increases and reaches its maximum at $t=\tau_{P}$. The maximum value of $n_{M}$,

$$
n_{M}=P_{0} \tau_{M}\left(1-\exp \left(-\frac{\tau_{\mathrm{P}}}{\tau_{M}}\right)\right)
$$

is expressed with the two characteristic times, $\tau_{P}$ and $\tau_{M}$. Again, $\tau_{P}$ is the time representing the duration of the production, and $\tau_{M}$ is the lifetime of $O\left({ }^{1} D\right)$, which characterizes the decay of the aurora. When the constant production ends, $n_{M}$ begins to decrease exponentially. At $t=\tau_{P}+\tau_{M}, n_{M}$ decreases to $1 / e$ of the maximum value (7). The decreasing phase, i.e., $\tau_{P}<t$, corresponds to the stage after the passage of the electron precipitation region.

\subsection{Comparison of Model With Observation}

Figure 8 shows the result of the least squares fitting of (5) and (6) to the variations of the observed auroral intensities for Event 4. The black dots indicate the auroral intensities observed at the $4 \mathrm{~s}$ interval, and the red curve is the result of the least squares fitting. The horizontal axis represents time $t$ expressed in seconds. The left vertical line represents the start time of the auroral enhancements for Event 4, i.e., 0727:10 UT, which is defined in Figure 3c. The right vertical line shows 0729:29 UT. At the latter time, the auroral intensity returned to a value close to that obtained at the start of the auroral intensification (left vertical line). We determined $t=0$ as $4 \mathrm{~s}$ before the start of the auroral enhancements (0727:06 UT =0726:10 UT $-4 \mathrm{~s}$ ), and we took the auroral intensity at $t=0$ as the baseline. Fitting was performed by using the data obtained after subtracting this baseline from the values observed between the two times given above (shown as vertical lines). We determined $\tau_{P}$ and $\tau_{M}$ with a time resolution of $10 \mathrm{~s}$.

The result of the fitting shows that $\tau_{P}=60 \mathrm{~s}, \tau_{M}=80 \mathrm{~s}$, and $f P_{0}=40 \mathrm{R} \mathrm{s}^{-1}$. In these results, we introduced the ratio $f$, which represents the proportionality of (5) or (6) to the actual auroral intensity. Figure 8 shows that the fitting is reasonably good. The estimated lifetime of $O\left({ }^{1} D\right), \tau_{M}=80 \mathrm{~s}$, is in the expected range, i.e., $30-$ $80 \mathrm{~s}$ [e.g., Sipler and Biondi, 1972]. The estimated duration of the production, $\tau_{P}=60 \mathrm{~s}$, is somewhat longer 


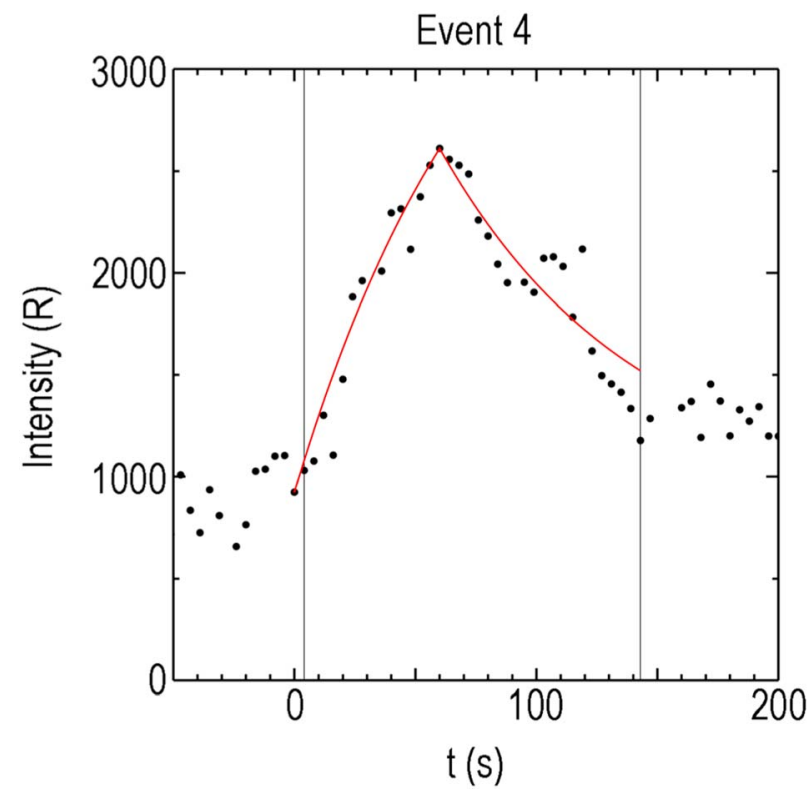

Figure 8. Result of least squares fitting (red curves) of equations (5) and (6) to the observed values (dots) for Event 4. The left vertical line represents the time for the start of the auroral enhancements, i.e., 0727:10 UT, which is defined in Figure 3c, and the right vertical line shows 0729:29 UT.

than the ESR one-integration time of $30 \mathrm{~s}$ during which $T_{e}$ was sharply enhanced (Event 4 in Figures $3 \mathrm{~b}$ and 3c). However, that difference is not significant considering that the time resolution of the ESR data is $30 \mathrm{~s}$. When we took $1 \mathrm{~km} \mathrm{~s}^{-1}$ as the typical speed of the electron precipitation region, as described in section 1 , the horizontal extent of the electron precipitation region traversed by the radar beam was $60 \mathrm{~km}\left(=1 \mathrm{~km} \mathrm{~s}^{-1} \times \tau_{P}\right)$. Although no electron precipitation was observed on the backside of that region, auroral emission did occur. Thus, the characteristic length of this extended part at the back is comparable to the horizontal scale of the electron precipitation region for this event. We will discuss the area ratio of the auroral emission region to the electron precipitation region later.

As shown in section 3.3, the variations in the auroral intensity in Events 1 and 3 were not the result of simple motion of the mesoscale auroral structure, and we did not perform fitting. For Event 2, we obtained $\tau_{P}=10 \mathrm{~s}$ and $\tau_{M}=50 \mathrm{~s}$. The latter again fits in the range implied by Sipler and Biondi [1972]. For Events 5-7, we did not perform fitting because the data around the maximum intensity were not correctly observed, as shown in Figure 3c. However, we can infer the time for the maximum intensity to an accuracy of $15 \mathrm{~s}$ for Event 7 because the interval of the "flat" intensities was relatively short (15 s). For the other two events, the interval was rather long at $59 \mathrm{~s}$ and $95 \mathrm{~s}$, respectively. When taking $t=0$ for Event 7 to be 0755:03 UT (= 0755:07 UT $-4 \mathrm{~s}$ ) in a manner similar as that for Event 4, we can infer that $\tau_{P}$ is $32 \mathrm{~s}(=0755: 35 \mathrm{UT}-0755: 03 \mathrm{UT})$ to $47 \mathrm{~s}$ (=0755:50 UT - 0755:03 UT). This duration is consistent with the ESR two-integration time of $60 \mathrm{~s}$ during which $T_{e}$ was sharply enhanced (Event 7 in Figures $3 b$ and 3c).

\subsection{Horizontal Profile of the Moving Cusp Aurora}

Finally, we discuss the horizontal extension of the auroral emission region. In the previous subsections, we discussed the temporal change in $\mathrm{O}\left({ }^{1} D\right)$ density and the auroral intensity at a fixed position, and we attributed these variations to the passage of the electron precipitation region. We assume here that the speed and size of the electron precipitation region is constant for a brief period such as a few minutes. We then substitute $t=L / V_{p}$ in (5) and (6), where $V_{P}$ is the constant speed of the electron precipitation region and $L$ is the length from the front edge of the electron precipitation region to the back. We express $\tau_{P}$ as $L_{P} / V_{P}$, where $L_{P}$ is the length of the electron precipitation region from its front edge to the trailing edge along its moving direction. As described in section 4.3, we introduced the ratio $f$ to explain $I$ instead of $n_{M}$. The following equations can be obtained for $l$ : 

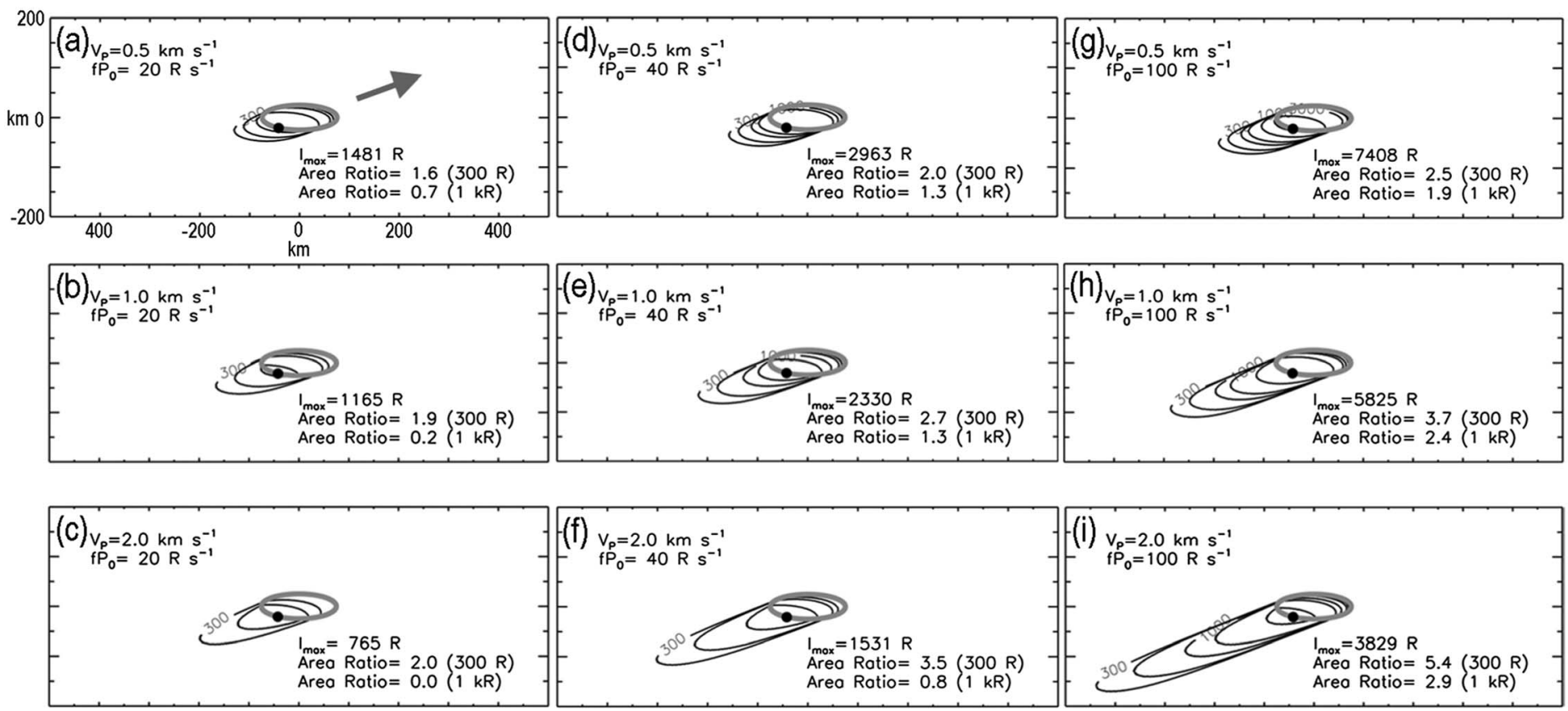

Figure 9. Calculation results of the horizontal extension of the $630 \mathrm{~nm}$ aurora emission region for nine conditions. (a-i) Each case has different values for two input parameters $V_{P}$ and $f P_{0}$. The values of these parameters are indicated at the top left of each figure. The gray arrow in Figure $9 a$ indicates the assumed direction of the moving electron precipitation region (gray elliptical shape). The small solid circle represents the location of the maximum auroral intensity. The contours show the intensities of $300 \mathrm{R}, 500 \mathrm{R}, 1 \mathrm{kR}, 1.5 \mathrm{kR}, 3.0 \mathrm{kR}$, and $6.0 \mathrm{kR}$. The obtained maximum intensity and the area ratio of the calculated auroral emission region, which is characterized by $300 \mathrm{R}$ or $1 \mathrm{kR}$, relative to the electron precipitation region are shown at the bottom right.

$$
\begin{gathered}
I=f P_{0} \tau_{M}\left(1-\exp \left(-\frac{L}{V_{P} \tau_{M}}\right)\right) \quad 0 \leq L \leq L_{P} \\
I=f P_{0} \tau_{M}\left(\exp \left(-\frac{L-L_{P}}{V_{P} \tau_{M}}\right)-\exp \left(-\frac{L}{V_{P} \tau_{M}}\right)\right) \quad L_{P}<L .
\end{gathered}
$$

Once the electron precipitation region and the direction of its motion have been determined, we can define various $L$ lines in which the origins are located at any point at the forward edge of the electron precipitation region. We can calculate the variations of the auroral intensity along each of those $L$ lines by using (8) and (9), and we can then obtain the two-dimensional distribution of $I$. For the shape of the electron precipitation region, we assumed an elliptical shape in which the major and minor axes were $150 \mathrm{~km}$ and $50 \mathrm{~km}$, respectively. These dimensions are consistent with previous observations. Taguchi et al. [2015a] adopted the area delineated by a semicircle with a diameter of $150 \mathrm{~km}$ for the mesoscale upward field-aligned current region, which is thought to be collocated with the electron precipitation region associated with the moving cusp auroral structure. Collocation of intense electron precipitation with a mesoscale upward field-aligned current in an event was also reported by Taguchi et al. [1993] (e.g., 0251:32 UT to 0251:40 UT in Plate 1 of that work). This interval of $8 \mathrm{~s}$ corresponds to the length of $64 \mathrm{~km}$ at the $F$ region height.

Figure 9 shows the results from the calculation of nine cases for $\tau_{M}=80 \mathrm{~s}$. In each figure, the assumed region of electron precipitation is represented by a gray line. The gray arrow in Figure 9a indicates that this region is moving along $22.5^{\circ}$ from the horizontal axis. The horizontal axis represents a length of $1000 \mathrm{~km}$, and the vertical axis shows a length of $400 \mathrm{~km}$, as also indicated in Figure 9a. The nine cases are characterized by three values of speed, $V_{P}=0.5,1.0$, and $2.0 \mathrm{~km} \mathrm{~s}^{-1}$, and three values of $f P_{0}=20,40$, and $100 \mathrm{R} \mathrm{s}^{-1}$. For $f P_{0}$, which represents the strength of the production rate, we used the value obtained from the data fitting (Figure 7), $40 \mathrm{R} \mathrm{s}^{-1}$ plus its one-half and 2.5 -fold values $\left(20 \mathrm{R} \mathrm{s}^{-1}\right.$ and $\left.100 \mathrm{R} \mathrm{s}^{-1}\right)$ for simplicity. The calculated maximum intensity is shown at the bottom right of each plot. The location of the maximum intensity is represented by the small solid circle. In each case, the black contours represent the auroral intensities. The outermost contour represents $300 \mathrm{R}$. At the bottom right, we also show the area ratio of the auroral emission region defined by 
$300 \mathrm{R}$ and $1 \mathrm{kR}$ to the electron precipitation region. It should be noted that we do not intend to explain the seven events shown in Figure 5 by the calculation of the nine cases shown in Figure 9.

Comparison of the results shown in Figures $9 a-9 c, 9 d-9 f$, and $9 g-9 i$ show that as the speed of the electron precipitation region increases, the auroral emission region is elongated. This tendency is independent of the value of $f P_{0}$. The results also show that as the speed of the electron precipitation region decreases, the maximum auroral intensity becomes stronger regardless of the value of $f P_{0}$. In all cases, the maximum auroral intensity occurs at a point along the trailing edge of the electron precipitation region. This point is located near the center of the entire structure of the auroral emission with an intensity of either $300 \mathrm{R}$ or $1 \mathrm{kR}$, although in the case of Figure $9 i$ the maximum point is far from the rear boundary of the auroral emission. This indicates the possibility that the motion of the electron precipitation can be estimated from the motion of the point at which the auroral intensity is the maximum within the entire auroral structure [Taguchi et al., 2015a]. For the cases of typical speed, $V_{P}=1 \mathrm{~km} \mathrm{~s}^{-1}$ (Figures $9 \mathrm{~b}, 9 \mathrm{e}$, and $9 \mathrm{~h}$ ), the area of the auroral emission is about 2 to 4 times that of the electron precipitation region when the area of auroral emissions is characterized by an intensity of $300 \mathrm{R}$. If the area of auroral emissions is characterized by an intensity of $1 \mathrm{kR}$, the area ratio is smaller.

In Figure 9 we assumed the size of the electron precipitation region and the direction of its motion. When we consider the case in which the elliptical region of electron precipitation moves along the horizontal axis rather than $22.5^{\circ}$ from the horizontal axis, the maximum intensity becomes stronger, and the auroral emission region is more elongated than those in Figure 9 owing to the larger $L_{P}$ in (8) and (9). On the other hand, if the region moves along the vertical axis, the maximum intensity becomes weaker, and the auroral emission region is smaller than those in Figure 9. The ratio of the maximum auroral intensities for these two cases can be obtained from (8) or (9) as follows:

$$
\frac{I_{h}}{I_{V}}=\frac{1-\exp \left(-\frac{L_{\mathrm{Pmax}}}{V_{\rho} \tau_{M}}\right)}{1-\exp \left(-\frac{L_{\mathrm{Pmin}}}{V_{P} \tau_{M}}\right)},
$$

where $I_{h}$ and $I_{v}$ represent the maximum auroral intensities for the cases in which the electron precipitation region moves along the horizontal and vertical axes, respectively, and $L_{P \max }$ and $L_{P \min }$ show the length of the major and minor axis, respectively.

When $L_{P \max }=150 \mathrm{~km}, L_{P \min }=50 \mathrm{~km}, V_{P}=1.0 \mathrm{~km} \mathrm{~s}^{-1}$, and $\tau_{M}=80 \mathrm{~s}$ are used in (10), we can obtain $I_{h} / I_{v} \sim 2$. This indicates that the direction of the motion of the electron precipitation region is also associated with the distribution of the auroral intensity. This indicates that the area of the electron precipitation itself, the speed and direction of the motion of that region, and the production rate control the size and shape of the $630.0 \mathrm{~nm}$ auroral emissions, which extend behind the electron precipitation region. That is, it is difficult to determine the part in which the electron precipitation occurs in the red line mesoscale aurora structure from only the information of the location of the maximum auroral intensity in a single auroral image. However, if we can estimate the speed and direction of the electron precipitation region from sequences of auroral images, we can better understand the horizontal extent of the electron precipitation in the red line auroral structure.

The results from our calculation agree with some of the features obtained in past research. Sandholt et al. [1986] showed that highly longitudinal extension of the $630.0 \mathrm{~nm}$ aurora is often observed with longitudinal movement. The longitudinal motion of the aurora appears when IMF is dawnward or duskward [e.g., Sandholt et al., 1986]. Under these IMF conditions, the convection in the cusp is strong in the longitudinal direction and tends to be fast [e.g., Knipp et al., 2011; Wilder et al., 2013]. Along with rapid convection, the electron precipitation region will move rapidly in the longitudinal direction. Our model shows that as the speed of the electron precipitation region increases, the auroral emission region is elongated, which creates a highly longitudinal extension of the aurora.

Fasel et al. [1992] reported phenomena in which poleward moving auroral structures have multiple intensifications during their movement. Our model suggests that the auroral intensity becomes stronger as the speed of the electron precipitation region decreases. If the convection slows down in the cusp, rebrightening of the moving aurora may occur. In fact, Fasel [1995] reported that some moving auroral structures slow down and stop while continuing to rebrighten. 
By examining a moving cusp aurora structure which has a typical horizontal scale of roughly $100 \mathrm{~km} \times 200 \mathrm{~km}$, Taguchi et al. [2015a] determined that the maximum $630.0 \mathrm{~nm}$ intensity of that auroral structure occurs immediately behind the moving $F$ region-enhanced electron density volume created by precipitating electrons. This spatial relationship agrees with the distribution obtained from our calculation.

We have suggested that the velocity of the electron precipitation region is important in determining the maximum intensity in the auroral structure and the horizontal extension of the auroral emission region behind the electron precipitation region. To extract the horizontal extension of the auroral emission region from all-sky image data more precisely, we need to consider the altitude profiles of the auroral emissions as well as the distribution of velocity $\boldsymbol{v}$ of the neutral $O\left({ }^{1} D\right)$ and the temporal variations of the production rate, which have not been considered in our estimates. The altitude for the $630.0 \mathrm{~nm}$ auroral emissions in the cusp may range from $200 \mathrm{~km}$ to at least $400 \mathrm{~km}$.

\section{Conclusions}

By investigating the all-sky images obtained with a time resolution of $4 \mathrm{~s}$ and comparing the results with the $30 \mathrm{~s}$ integrated $T_{e}$ measured simultaneously by ESR, we have shown the manner in which the moving cusp auroral structure passed though the ESR's field of view during 0700-0800 UT on 27 November 2011. In four of seven events, the radar's field of view cut across the central part of the moving mesoscale auroral structures. When the front edge of the auroral structure intersected the radar's field of view, the ESR electron temperature increased rapidly. A few minutes later, the electron temperature dropped to the background level, indicating that the electron precipitation region has passed through the radar's field of view. At that time, the auroral emission in the radar's field of view decreased but still had significant intensities without reaching the background level. These results provide direct evidence demonstrating that the moving red line cusp auroral emission occurs behind the electron precipitation region as well as in that region. That is, a moving cusp aurora does not have electron precipitation in its rear half. Our semiquantitative modeling based on the equation of continuity of the density of the excited atomic oxygen has shown that as the speed of the electron precipitation region increases, the auroral emission region is elongated. Moreover, our model shows that as the speed of the electron precipitation region decreases, the auroral intensity becomes stronger, and that the maximum auroral intensity occurs at a point along the trailing edge of the electron precipitation region. Therefore, the velocity of the electron precipitation region is an important factor for determining the distribution of $630.0 \mathrm{~nm}$ aurora emissions.

Acknowledgments

We would like to thank T. Aoki of University of Electro-Communications for his maintenance of the all-sky imager. We also thank F. Sigernes and M. Syrjäsuo for their help at the University Centre in Svalbard, Longyearbyen. The ground optical data used in this paper can be provided on request to $S$. Taguchi at Kyoto University. GEOTAIL magnetic field data were provided by $T$. Nagai through DARTS at the Institute of Space and Astronautical Science, JAXA in Japan (http://www.darts.isas.jaxa.jp/ stp/geotail). WIND data were obtained through NASA/CDAWeb (http://cdaweb.sci.gsfc.nasa.gov/index.html/). EISCAT data can be accessed through the EISCAT website (https://www.eiscat se/schedule/schedule.cgi). We are indebted to the director and staff of EISCAT for operating the facility and supplying the data. EISCAT is an international association supported by research organizations in China, Finland, Germany (until the end of 2011), Japan, Norway, Sweden, and the United Kingdom. This work was supported by JSPS KAKENHI grant 22340143, 26302006, and 15K05300.

\section{References}

Carlson, H. C., K. Oksavik, and J. I. Moen (2013), Thermally excited $630.0 \mathrm{~nm} \mathrm{O}\left({ }^{1} D\right)$ emission in the cusp: A frequent high-altitude transient signature, J. Geophys. Res. Space Physics, 118, 5842-5852, doi:10.1002/jgra.50516.

Doe, R. A., J. D. Kelly, and E. R. Sánchez (2001), Observations of persistent dayside $F$ region electron temperature enhancements associated with soft magnetosheathlike precipitation, J. Geophys. Res., 106(A3), 3615-3630, doi:10.1029/2000JA000186.

Fasel, G. J. (1995), Dayside poleward moving auroral forms: A statistical study, J. Geophys. Res., 100(A7), 11,891-11,905, doi:10.1029/95JA00854.

Fasel, G. J., J. I. Minow, R. W. Smith, C. S. Deehr, and L. C. Lee (1992), Multiple brightening of transient dayside auroral forms during oval expansions, Geophys. Res. Lett., 12, 2429-2432, doi:10.1029/92GL02103.

Haerendel, G., G. Paschmann, N. Sckopke, H. Rosenbauer, and P. C. Hedgecock (1978), The frontside boundary layer of the magnetosphere and the problem of reconnection, J. Geophys. Res., 83(A7), 3195-3216, doi:10.1029/JA083iA07p03195.

Hosokawa, K., S. Taguchi, Y. Ogawa, and T. Aoki (2013a), Periodicities of polar cap patches, J. Geophys. Res. Space Physics, 118, 447-453, doi:10.1029/2012JA018165.

Hosokawa, K., S. Taguchi, Y. Ogawa, and J. Sakai (2013b), Two-dimensional direct imaging of structuring of polar cap patches, J. Geophys. Res. Space Physics, 118, 6536-6543, doi:10.1002/jgra.50577.

Hosokawa, K., S. Taguchi, and Y. Ogawa (2016a), Edge of polar cap patches, J. Geophys. Res. Space Physics, 121, 3410-3420, doi:10.1002/ 2015JA021960.

Hosokawa, K., S. Taguchi, and Y. Ogawa (2016b), Periodic creation of polar cap patches from auroral transients in the cusp, J. Geophys. Res. Space Physics, 121, 5639-5652, doi:10.1002/2015JA022221.

Knipp, D., S. Eriksson, L. Kilcommons, G. Crowley, J. Lei, M. Hairston, and K. Drake (2011), Extreme Poynting flux in the dayside thermosphere: Examples and statistics, Geophys. Res. Lett., 38, L16102, doi:10.1029/2011GL048302.

Kozyra, J. U., C. E. Valladares, H. C. Carlson, M. J. Buonsanto, and D. W. Slater (1990), A theoretical study of the seasonal and solar cycle variations of stable auroral red arcs, J. Geophys. Res., 95, 12,219-12,234, doi:10.1029/JA095iA08p12219.

Lockwood, M., and H. C. Carlson Jr. (1992), Production of polar cap electron density patches by transient magnetopause reconnection, Geophys. Res. Lett., 19, 1731-1734, doi:10.1029/92GL01993.

Lockwood, M., H. C. Carlson Jr., and P. E. Sandholt (1993), Implications of the altitude of transient 630-nm dayside auroral emissions, J. Geophys. Res., 98(A9), 15,571-15,587, doi:10.1029/93JA00811.

Lockwood, M. P., E. Sandholt, S. W. H. Cowley, and T. Oguti (1989), Interplanetary magnetic field control of dayside auroral activity and the transfer of momentum across the dayside magnetopause, Planet. Space Sci., 37(11), 1347-1365, doi:10.1016/0032-0633(89)90106-2. 
Moen, J., P. E. Sandholt, M. Lockwood, W. F. Denig, U. P. Løvhaug, B. Lybekk, A. Egeland, D. Opsvik, and E. Friis-Christensen (1995), Events of enhanced convection and related dayside auroral activity, J. Geophys. Res., 100(A12), 23,917-23,934, doi:10.1029/95JA02585.

Oksavik, K., J. Moen, and H. C. Carlson (2004), High-resolution observations of the small-scale flow pattern associated with a poleward moving auroral form in the cusp, Geophys. Res. Lett., 31, L11807, doi:10.1029/2004GL019838.

Rees, M. H., and R. G. Roble (1975), Observations and theory of the formation of stable auroral red arcs, Rev. Geophys., 13(1), 201-242, doi:10.1029/RG013i001p00201.

Rees, M. H., and R. G. Roble (1986), Excitation of $O{ }^{1} D$ ) atoms in aurorae and emission of the [OI] 6300-A line, Can. J. Phys., 64(12), 1608-1613, doi:10.1139/p86-284.

Russell, C. T., and R. C. Elphic (1978), Initial ISEE magnetometer results-Magnetopause observations, Space Sci. Rev., 22, 681-715, doi:10.1007/BF00212619.

Sadler, F. B., M. Lessard, E. Lund, A. Otto, and H. Lühr (2012), Auroral precipitation/ion upwelling as a driver of neutral density enhancement in the cusp, J. Atmos. Sol. Terr. Phys., 87-88, 82-90, doi:10.1016/j.jastp.2012.03.003.

Sakai, J., K. Hosokawa, S. Taguchi, and Y. Ogawa (2014), Storm-time enhancements of 630.0-nm airglow associated with polar cap patches, J. Geophys. Res. Space Physics, 119, 2214-2228, doi:10.1002/2013JA019197.

Sandholt, P. E., C. S. Deehr, A. Egeland, B. Lybekk, R. Viereck, and G. J. Romick (1986), Signatures in the dayside aurora of plasma transfer from the magnetosheath, J. Geophys. Res., 91(A9), 10,063-10,079, doi:10.1029/JA091iA09p10063.

Sandholt, P. E., M. Lockwood, T. Oguti, S. W. H. Cowley, K. S. C. Freeman, B. Lybekk, A. Egeland, and D. M. Willis (1990), Midday auroral breakup events and related energy and momentum transfer from the magnetosheath, J. Geophys. Res., 95(A2), 1039-1060, doi:10.1029/ JA095iA02p01039.

Sipler, D. P., and M. A. Biondi (1972), Measurements of O ( ${ }^{1} D$ ) quenching rates in the F region, J. Geophys. Res., 77(31), 6202-6212, doi:10.1029/ JA077i031p06202.

Southwood, D. J. (1987), The ionospheric signature of flux transfer events, J. Geophys. Res., 92(A4), 3207-3213, doi:10.1029/JA092iA04p03207.

Suzuki, S., S. Taguchi, K. Hosokawa, M. R. Collier, T. E. Moore, H. U. Frey, and S. B. Mende (2008), Conjugate observations of ENA signals in the high-altitude cusp and proton auroral spot in the low-altitude cusp with IMAGE spacecraft, Geophys. Res. Lett., 35, L13103, doi:10.1029/ 2008 GL034543.

Taguchi, S., M. Sugiura, J. D. Winningham, and J. A. Slavin (1993), Characterization of the IMF $B_{Y}$-dependent field-aligned currents in the cleft region based on DE 2 observations, J. Geophys. Res., 98, 1393-1407, doi:10.1029/92JA01014.

Taguchi, S., S. Suzuki, K. Hosokawa, Y. Ogawa, A. S. Yukimatu, N. Sato, M. R. Collier, and T. E. Moore (2009), Moving mesoscale plasma precipitation in the cusp, J. Geophys. Res., 114, A06211, doi:10.1029/2009JA014128.

Taguchi, S., K. Hosokawa, Y. Ogawa, T. Aoki, and M. Taguchi (2012), Double bursts inside a poleward-moving auroral form in the cusp, J. Geophys. Res., 117, A12301, doi:10.1029/2012JA018150.

Taguchi, S., K. Hosokawa, and Y. Ogawa (2015a), Three-dimensional imaging of the plasma parameters of a moving cusp aurora, J. Atmos. Sol. Terr. Phys., 133, 98-110, doi:10.1016/j.jastp.2015.08.012.

Taguchi, S., K. Hosokawa, and Y. Ogawa (2015b), Investigating the particle precipitation of a moving cusp aurora using simultaneous observations from the ground and space, Prog. Earth Planet. Sci., 2, 11, doi:10.1186/s40645-015-0044-7.

Vorobjev, V. G., G. Gustafsson, G. V. Starkov, Y. I. Feldstein, and N. F. Shevnina (1975), Dynamics of day and night aurora during substorms, Planet. Space Sci., 23, 269-278, doi:10.1016/0032-0633(75)90132-4.

Watermann, J., D. Lummerzheim, O. de laBeaujardière, P. T. Newell, and F. J. Rich (1994), lonospheric footprint of magnetosheathlike particle precipitation observed by an incoherent scatter radar, J. Geophys. Res., 99, 3855-3867, doi:10.1029/93JA01995.

Wilder, F. D., S. Eriksson, H. Korth, J. B. H. Baker, M. R. Hairston, C. Heinselman, and B. J. Anderson (2013), Field-aligned current reconfiguration and magnetospheric response to an impulse in the interplanetary magnetic field $B_{Y}$ component, Geophys. Res. Lett., 40, 2489-2494, doi:10.1002/grl.50505. 